\title{
Nay de Gambia y su himno a la libertad
}

(Fernández Ochoa, Adelaida. La hoguera lame mi piel con cariño de perro.

Colombia: Universidad del Valle, 2015.)

\author{
Daiana Nascimento dos Santos \\ Centro de Estudios Avanzados \\ Universidad de Playa Ancha.Valparaíso, Chile \\ daiana.nascimento@upla.cl
}

La hoguera lame mi piel con cariño de perro ${ }^{1}$ es una novela publicada en 2015 en Colombia por la crítica literaria Adelaida Fernández Ochoa sobre la vida de Nay de Gambia, la esclava de María de la novela homónima de Jorge Isaacs publicada en 1867. La novela de Adelaida recrea literariamente el imaginario de Colombia colonial bajo las miradas de Nay de Gambia y de su hijo Sundiata.

La saga de Nay está marcada por la tragedia familiar, por muertes, violencia, estupros, pérdidas y varias formas de esclavitud. Sin embargo, su historia no sólo se construye de tragedias, sino también muestra señales de sobrevivencia, revitalización, superación, resistencias colectivas y empoderamiento de la mujer negra.

La hoguera lame mi piel con cariño de perro remite a una versión de la historia no oficial colombiana de mujeres y niños esclavizados, a través de los relatos de Nay y de Sundiata. A lo largo de los relatos se evidencian la complicidad entre madre e hijo, las diversas formas de resistencia y el afán de retornar a África. Estas experiencias atraviesan varias novelas que han tratado de recrear el imaginario de la mujer negra esclavizada. El último aspecto (retorno a África) es experimentado, además, por el personaje Luisa Gama/ Kehinde de la novela brasileña Um defeito de cor (2006) de Ana Maria Gonçalves.

La historia se desarrolla en el periodo colonial de Colombia, donde los eventos se encuentran imbricados con la cotidianidad de los personajes (históricos y ficticios) y cuyo trasfondo histórico es el Valle del Cauca en la Colombia del siglo XIX.

Aparte de narrar, en sus casi doscientas páginas, la búsqueda de Nay por Sinar -su gran amor-, el texto entrega una reformulación de África en relación a la esclavitud,

\footnotetext{
${ }^{1}$ Premio Casa de las Américas de Novela 2015.
} 
desde una perspectiva contemporánea de conciencia social, que explora las infinitas posibilidades para leer la historia silenciada por tanto tiempo, y la vez, urge por la recuperación de los vínculos ancestrales: “No, ya no busco a Sinar, sólo quiero volver porque entre África y yo hay una herida que sangra y yo la voy a cerrar; para eso quiero volver” (164). En este sentido, este retorno posee connotaciones muy significativas tanto a nivel literario cuanto dentro de los estudios sobre ÁfricAmérica.

A nivel literario, se sitúa como versión otra de la novela María (1867) de Jorge Isaacs, como bien explica Adelaida en el prólogo: "Me propuse superar la interpretación canónica imperante en la cual la presencia de los esclavos está perdida y no tienen protagonismo” (11). Dentro de los estudios sobre ÁfricAmérica, encierra la importancia de recuperar/visibilizar el vínculo ancestral, las demandas sociales y las resistencias actuales del pueblo colombiano de origen africano. Labor iniciada por el maestro Manuel Zapata Olivella. Además, este retorno reitera la importancia de reconciliarse consigo mismo como grupo colectivo africano descendiente. Miampika explica que es necesario que haya una reconciliación de este sujeto con su pasado histórico y consigo mismo (2000:36). Estos aspectos cimentan los ideales del recorrido de Nay de Gambia hacía sí misma y hacía su libertad en tierras africanas:

No me he alejado de mí. La casa grande ha querido desviar mis ideales hacia los suyos; que yo derive alegría de sus blancas alegrías, sueños de sus realizados paraísos, que sea testigo sentimental de sus blancas vidas. Pero yo conozco mis goces propios y no quiero dejar de ser yo (41).

La hoguera lame mi piel con cariño de perro instala una alteración del rol representativo para las discusiones sobre la historia de la esclavitud desde la mirada femenina, lo que se refuerza en la máxima „Mujer negra tiene historiae (Rufino et. all 1987). Se trata, por lo tanto, de un proyecto ficcional que rescata la historia desde la perspectiva de los vencidos, y con este fin otorga un rol significativo al sujeto femenino en cuanto mujer y negra. Adelaida, al hacerse cargo de un proyecto literario que permite reflexionar desde esta perspectiva, reivindica el rol protagónico de la mujer negra/africanodescendiente en las diversas camadas de la sociedad colombiana tanto a nivel histórico, literario, político, como en cualquier rol que cumpla en esta sociedad. Se concluye, por lo tanto, que la novela entona un Himno a la libertad de hombres, mujeres y niños todavía en situación de esclavitud en el siglo XXI. 


\section{Bibliografía}

Cabrera, Patricia Muñoz. Narrativas emancipatorias en la literatura afroestadunidense contemporánea: el caso de Gayl Jones. In Caicedo, Martha Luz Machado (ed.) La diáspora africana: un legado de resistencia y emancipación. Santiago de Cali: Fucla, 2012:133- 160. Impreso.

Miampika, Landry-Wilfrid (comp.). África a varias voces: cantos y ecos: Voces africanas. Madrid: Verbum, 2000. Impreso.

Rufino, Alzira, Pereira, Maria Rosa y Iraci, Nilza. Cartilha: mulher negra tem história. Santos: Eboh Ed. e Livraria, 1987. Impreso.

Santos, Daiana Nascimento dos. El océano de fronteras invisibles: relecturas históricas sobre (¿el fin? de) la esclavitud en la novela contemporánea. Madrid: Editorial Verbum, 2015. 